\title{
SQUAMOUS CELL CARCINOMA OF NASAL VESTIBULE: A CASE REPORT
}

Gayattre Kailas ${ }^{1}$, Muniraju $\mathrm{M}^{2}$, Vidya $\mathrm{H}^{3}$

\section{HOW TO CITE THIS ARTICLE:}

Gayattre Kailas, Muniraju M, Vidya H. "Squamous Cell Carcinoma of Nasal Vestibule: A Case Report". Journal of Evolution of Medical and Dental Sciences 2015; Vol. 4, Issue 27, April 02; Page: 4711-4715,

DOI: $10.14260 /$ jemds $/ 2015 / 682$

\begin{abstract}
Various types of diseases can involve the nasal vestibule. Diagnosis and treatment of a nasal vestibular mass is often challenging due to the anatomical features of the nasal vestibule. Here, we report a histologically proven case of squamous cell carcinoma of nasal vestibule in a female patient.
\end{abstract}

KEYWORDS: Nasal vestibule, Squamous cell carcinoma, Radiotherapy.

INTRODUCTION: The nasal vestibule is a pear-shaped space $1.5-2.0 \mathrm{~cm}$ in maximum diameter that forms the entrance of the nasal cavity. It is lined by skin containing sebaceous glands and hair follicles. The vestibule is surrounded laterally by the lower (alar) cartilage and extends posteriorly to the limen nasi, a ridge of tissue that marks the mucocutaneous junction approximately $2 \mathrm{~cm}$ from the vestibule entrance and corresponds to the upper margin of the alar cartilage. The medial wall of the vestibule is the columella, which is formed by the medial wing of the alar cartilage and is $4-6 \mathrm{~mm}$ wide. The columella is separated from the cartilaginous septum by the thin membranous septum. The floor of the vestibule is approximately $1 \mathrm{~cm}$ long and is formed by skin overlying the superior aspect of the hard palate.

Nasal vestibule cancers are usually squamous cell carcinomas; the majority is well to moderately differentiated ${ }^{1-5}$. They are essentially skin cancers and have a different natural history and more favorable prognosis than nasal cavity malignancies.1,6,7 Primary tumors are usually relatively limited at presentation (T1-T2); most are $<5 \mathrm{~cm}$ in diameter with no evidence of cartilage or bone invasion. $5,8-10$ Because almost all tumors $>5 \mathrm{~cm}$ in diameter have cartilage or bone invasion, T3 tumors are rare. 5 Patients with T4 cancers can be stratified into a larger favorable subset with lesions $<4 \mathrm{~cm}$ in diameter with no bone invasion, and a smaller subset with unfavorable tumors, $>4$ $\mathrm{cm}$ in diameter and usually associated with invasion of the premaxilla or, less commonly, the bony septum. ${ }^{9,11}$

The incidence of clinically positive nodes is $5 \%$ to $15 \%$ at diagnosis; another $10 \%$ will develop metachronous lymph node metastases during the course of the disease.1,5,6,9,10 The incidence of positive nodes is greater in patients with advanced and/or recurrent primary tumors. Lymphatic spread is usually to a solitary submandibular or facial lymph node, but may occasionally be bilateral. Patients are usually male with an average age of 60-65 years (Range, approximately 40-80 years). ${ }^{1,3-5,9,12}$ Nasal vestibule carcinomas may be treated with either radiation therapy or surgery. ${ }^{12}$

CASE REPORT: A 62 year old female patient came to ENT outpatient department with complaints of right sided nasal obstruction and mass in the right side of nasal cavity since 6 months.

ON EXAMINATION: Diffuse swelling on the right side of nose (Figure 1) with obliteration of nasomaxillary groove, there was a growth protruding from the right nasal vestibule, pinkish in colour 


\section{CASE REPORT}

the irregular surface, probe test showed that it was sensitive to touch, firm in consistency, bleeds on touch, probe cannot be passed on the lateral aspect.

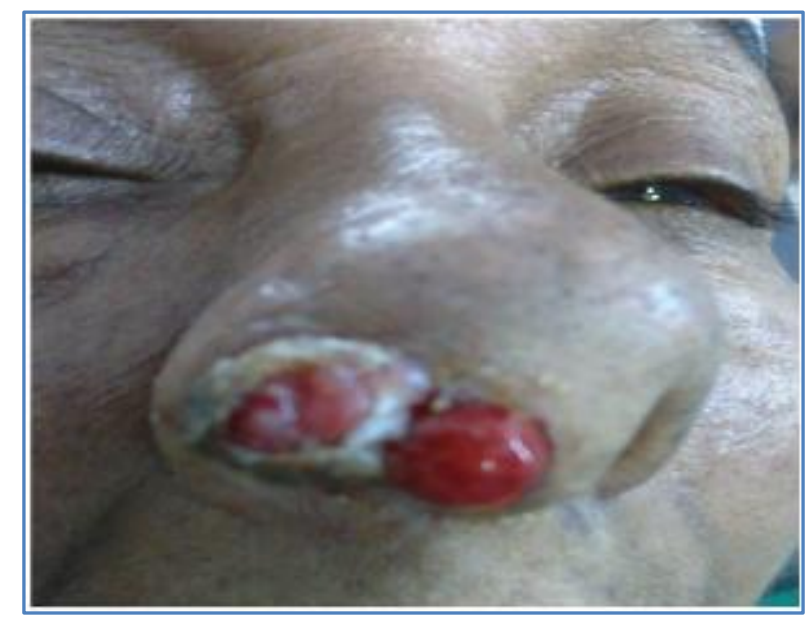

\section{Fig. 1}

RADIOLOGY: CT scan of PNS.

Contrast enhanced CT scan of PNS (Figure 2) was done which showed a polypoidal heterogeneously enchancing soft tissue density lesion measuring about $2.2 \times 1.4 \mathrm{~cm}$ seen arising from the inner surface of the right antero inferior nasal cavity near the nostril. There was no evidence of bone erosion.

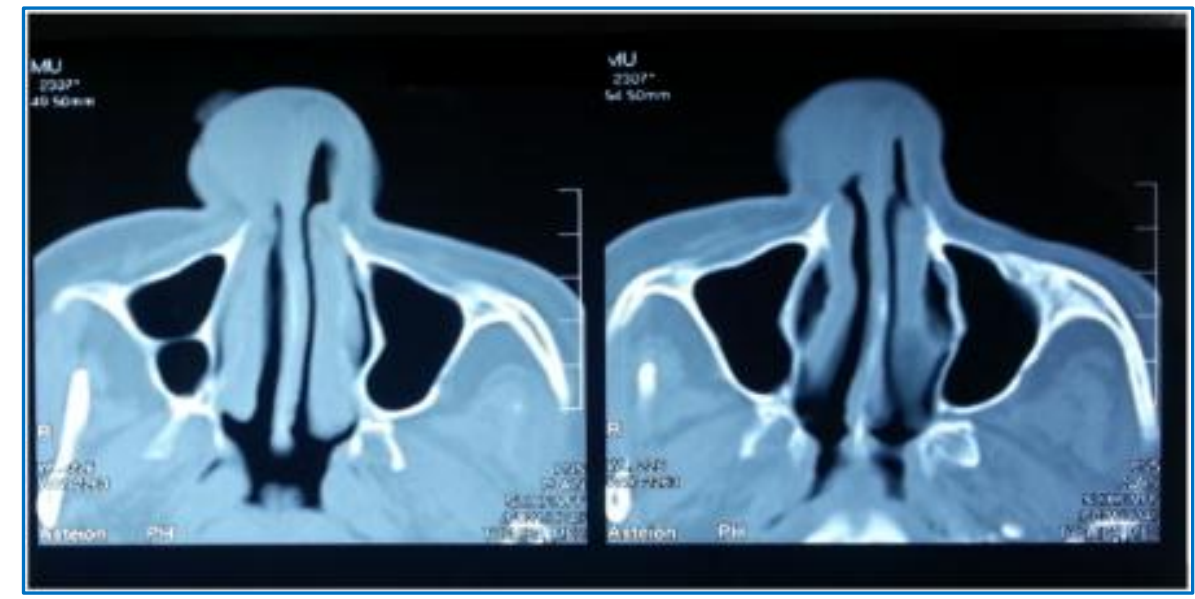

\section{Fig. 2}

Clinically a differential diagnosis of rhinosporidiosis, inverted papilloma, and malignant tumor of nasal cavity was given. Other routine investigations were within normal limits and patient was posted for complete excision of the mass.

TREATMENT: Complete excision of the mass was done with cauterization of the base. The mass was sent for HPE. 
HISTOPATHOLOGICAL EXAMINATION: Gross specimen: Specimen consists of two irregular grey white to grey brown soft tissue masses largest measuring $2.5 \times 1.3 \times 0.5 \mathrm{cms}$ and smaller one measuring $1 \mathrm{x} 1 \mathrm{x} 0.5 \mathrm{cms}$. Cut surface showed grey white to grey brown areas.

Microscopy: Sections studied shows features of moderately differentiated squamous cell carcinoma.

\section{POST-OPERATIVE FOLLOW UP:}

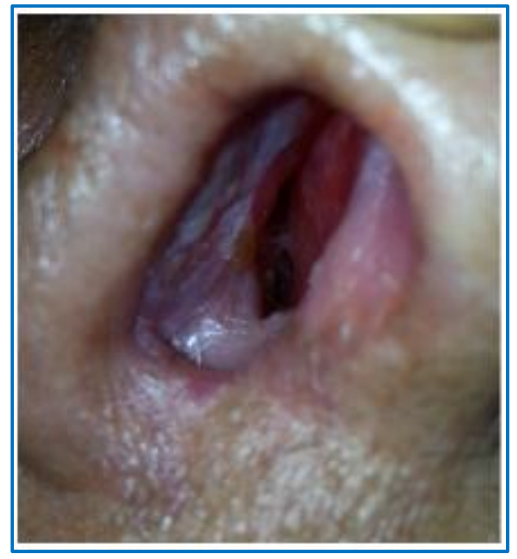

\section{Fig. 3}

Post-operative CT scan of PNS was done, which was normal and patient was advised radiotherapy.

DISCUSSION: Squamous cell carcinoma (SCC) of the nasal vestibule is a rare condition. Surgery and radiotherapy are the most commonly used therapy entities, but no golden standard has been defined.

T-classification for cancers of the nasal vestibule proposed by Wang.

T1: The lesion is limited to the nasal vestibule, relatively superficial, involving one or more sites within.

T2: The lesion has extended from the nasal vestibule to its adjacent structures, such as the upper nasal septum, upper lip, philtrum, skin of the nose and/or the nasolabial fold, but not fixed to the underlying bone.

T3: The lesion has become massive with extension to the hard palate, buccogingival sulcus, and large portion of the upper lip, upper nasal septum, and turbinate and/or adjacent paranasal sinuses, fixed with deep muscle or bone involvement.

\section{Union Internationale Contre Le Cancer (2002) classification:}

T1: Limited to one subsite.

T2: Involves two subsites or adjacent nasoethmoidal site.

T3: Invasion of medial wall/ floor orbit, maxillary sinus, palate, cribriform plate.

T4a: Involvement of anterior orbit, skin of nose/cheek, anterior cranial fossa, pterygoid plates, sphenoid/ frontal sinuses.

T4b: Involvement of orbital apex, dura, brain, middle cranial fossa, cranial nerves other than V2, nasopharynx, clivus. 


\section{CASE REPORT}

Squamous cell carcinoma of nasal vestibule behaves quite differently from carcinoma of the skin and presents problems in therapeutic management both to the surgeons and to the radiation therapist. The small, limited lesions can be treated either by surgery ${ }^{13,14}$ or by radiation therapy ${ }^{15}$ alone with a satisfactory cure rate. The choice of treatment modality depends upon the cosmetic result following the procedure. If significant deformity or mutilation will result following surgery, radiation therapy should be the treatment of choice. Radiation therapy for these lesions calls for high dose of irradiation to a small volume of tissue.

For TI and early T2 lesions, radiation therapy can be delivered by a combination of external beam orthovoltage therapy, or electron beam therapy, and interstitial implant without significant radiation complications. For extensive $\mathrm{T}$ lesions, radical surgery with or without preoperative radiation therapy employing megavoltage technique is preferred. Nodal metastases are treated by preoperative radiation therapy and radical neck dissection. Because of the relatively low incidence of nodal metastases for the small limited lesions (Approximately 10\%), elective neck irradiation or dissection is not warranted.

CONCLUSION: Most patients with squamous cell carcinoma of the nasal vestibule have relatively limited lesion with a high likelihood of local control after either radiation therapy or surgery. Resection is a reasonable alternative if the lesion can be removed with a good functional and cosmetic result; otherwise, the preferred treatment is radiation therapy. For the correct diagnosis and corresponding optimal treatment of a vestibular mass, an interdisciplinary approach is of paramount importance.

\section{REFERENCES:}

1. Goepfert H, Guillamondegui OM, Jesse RH, Lindberg RD. Squamous cell carcinoma of nasal vestibule. Arch Otolaryngol 1974; 100: 8-10.

2. Haynes WD, Tapley ND. Radiation treatment of carcinoma of the nasal vestibule. Am J Roentgenol 1974; 120: 595-602.

3. Baris G, Visser AG, Van Andel JG. The treatment of squamous cell carcinoma of the nasal vestibule with interstitial iridium implantation. Radiother Oncol 1985; 4: 121-125.

4. De Jong JMA, Schalekamp W, Hordijk GJ. Squamous carcinoma of the nasal vestibule. Clin Otolaryngol 1981; 6: 205-208.

5. Poulsen M, Turner S. Radiation therapy for squamous cell carcinoma of the nasal vestibule. Int J Radiat Oncol Biol Phys 1993; 27: 267-272.

6. Wang CC. Treatment of carcinoma of the nasal vestibule by irradiation. Cancer 1976; 38: 100106.

7. Parsons JT, Kimsey FC, Mendenhall WM, Million RR, Cassisi NJ, Stringer SP. Radiation therapy for sinus malignancies. Otolaryngol Clin North Am 1995; 28: 1259-1268.

8. American Joint Committee on Cancer. Manual for staging of cancer, 4th ed. Philadelphia: J. B. Lippincott; 1992. Pp 137-141.

9. Wong CS, Cummings BJ, Elhakim T, Briant TD. External irradiation for squamous cell carcinoma of the nasal vestibule. Int J Radiat Oncol Biol Phys 1986; 12: 1943-1946.

10. Kagan AR, Nussbaum H, Rao A, et al. The management of carcinoma of the nasal vestibule. Head Neck Surg 1981; 4: 125-128. 


\section{CASE REPORT}

11. McCollough WM, Mendenhall NP, Parsons JT, et al. Radiotherapy alone for squamous cell carcinoma of the nasal vestibule: Management of the primary site and regional lymphatics. Int J Radiat Oncol Biol Phys 1993; 26: 73-79.

12. Levendag PC, Pomp J. Radiation therapy of squamous cell carcinoma of the nasal vestibule. Int J Radiat Oncol Biol Phys 1990; 19: 1363-1367.

13. Gray's Anatomy, 29th ed. Philadelphia, Lea and Febiger, 1973.

14. Yarington, C. T., Jaquiss, G. W., and Sprinkle, P. M.: Carcinoma of the nose and nasal septumTreatment and reconstruction. Trans. Am. Acud. Ophthalmol. Otolaryngol. 73: 1178-1183, 1969.

15. Haynes, W. D., and Tapley, N. V.: Radiation treatment of carcinoma of the nasal vestibule. Am. J. Roentgenol. Radium Ther. Nucl. Med. 120: 595-602, 1974.

\section{AUTHORS: \\ 1. Gayattre Kailas \\ 2. Muniraju M. \\ 3. Vidya $\mathrm{H}$.}

\section{PARTICULARS OF CONTRIBUTORS:}

1. Lecturer, Department of ENT, Dr. B. R. Ambedkar Medical College, Bangalore.

2. Professor, Department of ENT, Dr. B. R. Ambedkar Medical College, Bangalore.

3. Junior Resident, Department of ENT, Dr. B. R. Ambedkar Medical College, Bangalore.

FINANCIAL OR OTHER COMPETING INTERESTS: None

\section{NAME ADDRESS EMAIL ID OF THE CORRESPONDING AUTHOR:}

Dr. Gayattre Kailas,

No. 26, $1^{\text {st }}$ Floor, $1^{\text {st }} \mathrm{B}$ Cross, RMV Extension, Near Mekhri Circle, Bangalore-80.

E-mail: gayathrikailash2000@yahoo.com

Date of Submission: 09/03/2015.

Date of Peer Review: 10/03/2015.

Date of Acceptance: 20/03/2015.

Date of Publishing: 02/04/2015. 